\title{
Information System Success in Tanzania Customs Operations: Taxpayers' Optimism Bias and Perceived Ease of Use
}

\author{
Joyce Sichone \\ Institute of Tax Administration (ITA), P.O. Box 9321, Dar Es Salaam, Tanzania
}

\begin{abstract}
This study aimed at investigating the information systems (IS) success from activities rendered by different actors in customs clearance operations in Tanzania. Specifically, the study intended to assess users' optimism bias perception and perceived ease of use due to challenges encountered in clearance of cargo. To attain the study objectives, primary data was collected from 223 tax practitioners and taxpayers from Customs and Excise Department of the Tanzania Revenue Authority. Descriptive analysis was used to summarize the data. Besides, principal component analysis assisted in determining the constructs of the study. Subsequently, confirmatory factor analysis was run for data validity; whereas, structural equation modeling tested the developed hypotheses. The study found that optimism bias and perceived ease of use were both positively and significantly associated with IS success in customs clearance operations. The study recommends provision of user friendly systems and reliable website applications for taxpayers continual usage of the developed systems for IS success. Furthermore, the study provides useful inputs relevant to different stakeholders such as researchers useful for future research as well as practitioners, especially tax administrators.
\end{abstract}

Keywords: IS success, optimism bias, perceived ease of use

DOI: $10.7176 / \mathrm{IKM} / 9-3-02$

Publication date:March $31^{\text {st }} 2019$

\section{Introduction}

Information System (IS) success in customs activities is helpful in enhancing efficiency. For instance, efficiency can be reflected in reducing delay time encountered by taxpayers during release of goods for intended purposes. Okazaki (2018) indicates reduced time (that also ends on cost reduction) as a good indicator to customs procedures' performance. The stated time encompassing the period associated with several activities rendered by other governmental agencies as well as by port and border authorities. Unfortunately, though there are electronic services (e-services) initiatives by governments in tax operations (Bhuasiri et al. 2016), most customs activities like clearance procedures delay and encounter other cross border activities' challenges (Arvis et al. 2016; Okazaki 2018). The delay may be caused by various factors including IS success factors such as taxpayers optimism bias - how taxpayers feel that they are capable in e-services (Styvén et al. 2014); as well as their perception on ease of using developed systems (Rana et al. 2015). Perceived ease of use of the system leads the respondents toward their behavioral intentions useful for IS success for implementation of customs' activities.

The use of IS in operations is not sufficient to cover every aspect in clearance of goods. There are other concerns associated with release of goods and cross border business in general (Arvis et al. 2016). Global trends of cross border business show that developing economies especially African countries are at a disadvantaged position as they face more problems as compared to their counterparts. These problems might call for reforms on investments, port operations and trade facilitation. Developing countries tend to import lower value types of 
goods (cars, clothes and the like) than developing economies; and due to connectivity concerns (digital issues), developing countries lag behind in business performance. For example, by use of modernization, cost of doing activities is expected to reduce. Contrary, developing counties (mainly in Africa) have been observing higher freight charges (average of 12.2\% in 2016) as compared to developing countries in America (Okazaki 2018). In such trend, these challenges in business operations including clearance of goods need proper attention (Arvis et al. 2016; Bhuasiri et al. 2016). The challenges in clearance of goods cover issues associated with IS as determined by users' perception; as well as concerns of various actors and bodies participating in the trade logistics chain for movement of goods across borders. Tanzania, one of the developing countries faces related challenges. Most of her neighbor countries (such as Malawi) are land locked, and depend on efficient operations of Tanzania customs clearance to facilitate cross boarder activities (termed as transit operations).

Tanzania import process is guided by the East African Customs Management Act (EACCMA) 2004 (Tanzania Revenue Authority 2017). Clearing process of the cargo from abroad is as follows: the master of the conveyance submits manifest to Customs. Clearing agent receives shipping documents at least 5 days prior to arrival of the vessel. After preparing documents for Home Affairs purposes, the documents are sent to Customs Service Centre. Documents include bill of lading, invoice, packing list, pertaining to Tanzania Bureau of Standards (TBS), radiation and permits. The documents are matched with the manifest. Depending on risk level, a cargo can be marked green channel, for direct release; yellow - documentary check; or red channel, which is $100 \%$ physical verification. A release order is issued for red and yellow channels after conforming to the requirements. The loaded trucks are released out of the port after the clearing agent submits road or railway truck list (EACCMA 2004; Tanzania Revenue Authority 2017). These activities are handled through an integrated system - TANCIS.

TANCIS replaced the previous customs management system - ASYCUDA++ that had been in use in Tanzania since 2005 (Tanzania Revenue Authority 2017). The Tanzania Customs Integrated System (TANCIS) implemented early 2014, simplifies the process of clearing import and export of goods through port, airport and border posts. Some of the consignments are attached with duty payment which can be done through banks integrated with TANCIS. Amana Bank is among the organizations used for the tax payment operation. This bank facilitates payment of customs duty to Tanzania Revenue Authority (TRA) using TANCIS. The system is built on hi-tech principles. Also Tanzania Single Administrative Document - TANSAD, an assessment form from TRA is being attached to the system. The use of TANCIS is very beneficial since it helps to enhance efficiency, transparency, effectiveness and reliability in the Customs administration. TANCIS facilitates paperless operations leading to a significant reduction in costs of doing business as it is a web based system. Besides, TANCIS is used in many other associated clearance activities, for instance, the documents from shipping agencies are covered under the system. Unfortunately, due to users' attitudes, some of the taxpayers (clearing agents) as experienced by shipping agents, struggle to enquire in person these documents. Besides, several challenges face governments while implementing activities mostly for modernization purposes. Chimilila et al. (2014) indicate major challenges to include low capacity to both human and financial resources as well as low level of automation. Another challenge encountered by most governments is engaging and retaining users for continual usage of e-government services since in most cases after initial usage, citizens revert to manual ways of acquiring government services (Teo et al. 2008), which is also experienced in Tanzania tax operations. Due to 
such instances, this study sought to assess taxpayers' perceptions about their own ability that contributes to IS success through intention usage of public e-services. Therefore, the study assessed the influence of optimism bias on government e-service in tax operations; and how taxpayers view the perceived ease of using developed systems which might be a stumbling block on IS success as far as customs clearance of goods is concerned. Perceived ease of use variable was adopted from Technology Acceptance Model while optimism bias from Ramayah et al. (2009). Consequently, the rest of this paper proceeds with the literature review (theoretical as well as empirical frameworks) and the hypotheses. Subsequently, the methodology of the study; research findings and discussion of the results are presented. Finally, conclusions, recommendations, limitations and suggestions for further research are discussed.

\section{Literature Review}

The meaning of IS success has not been homogeneous across researches, as it is dependent upon the context of the study. IS success models have been trying to provide variables helpful in understanding this concept. Depending on study situation, some acceptance theories like the Technology Acceptance Model have been used to understand IS and its operations.

\subsection{Technology Acceptance Model (TAM)}

This study was informed by TAM since it is widely applied (by $22^{\text {nd }}$ January 2018 - cited by 42590, Google Scholar), is accepted and has been supported by empirical studies as well. TAM, developed by Davis (1989), has its grounds in the theory of reasoned action (Fishbein \& Ajzen 1975). The model states that users are motivated to use the system by two main reasons: perceived ease of use and perceived usefulness. Perceived usefulness is the users' expectation that by adopting new technology could results into improvement of work performance, while perceived ease of use is the degree to which a person expects that using a particular system would be free of effort (Davis 1989). This theory has been widely applied by studies that focus on acceptance of information systems; mostly being modified and extended. Through such modifications, TAM2, TAM3 and the Unified Theory of Acceptance and Use of Technology (UTAUT) were developed. TAM2 opines that users may have positive perception to IS if they see positive results (Venkatesh \& Davis 2000). TAM 3 includes variables trust and perceived risk on system use especially in e-commerce context. UTAUT states that one's behavioural intention to use established technology is influenced by performance expectancy, facilitating conditions, social influence and effort expectancy (Venkatesh et al. 2003). Furthermore, six variables (prior experience, other's use, system quality, computer anxiety, organizational support and task structure) that affect system usage have been suggested for modification (McFarland \& Hamilton 2006). The proposed modifications from initial model were covering some observed limitations so as to determine latent factors underlying perceived ease of use and perceived usefulness. As TAM explains the causal relationships between internal psychological variables (beliefs, attitudes, and behavioural intention) and actual system usage; this study applied it for taxpayers' perceptions in cargo clearance operations. Taxpayers' perceptions in e-services to such operations indicate their motivation of usage intention that explains IS success (Ventatesh et al. 2012). 


\subsection{Empirical Framework}

Empirical literature shows several factors relevant for IS success such as performance expectance, perceived risk, ease of use, optimistic bias and facilitating conditions (Chaouali et al. 2016; Charfeddine \& Nasri 2013; Moorthy et al. 2014). Due to mandatory systems of e-services in Tanzania, it was relevant to investigate on the perceived ease of use and optimistic bias to obtain taxpayers views for the improvement of IS operations. The study, therefore, dealt with tax matters especially goods clearance since though the government operates eservices there is still delay in release of cargo.

Perceived ease of use is sometimes termed as effort expectancy, which is the degree to which the systems are easy to use (Venkatesh et al. 2003). This construct (perceived ease of use) may be supported by taxpayers' ICT knowledge and experience (Anees \& Kumar 2017). Building on the arguments, Kumar \& Gupta (2017) recommend user friendly systems. A study in India by Rana et al. (2015) observed that perceived ease of use of the system leads the respondents toward their behavioral intentions useful for IS implementation success. Likely, Teo \& Zhou (2014) show that perceived ease of use influences intention to use developed technology through attitude towards computer use. Bhuasiri et al. (2016) and Borrero et al. (2014) observed that if taxpayers or ICT users are competent, then perceived ease of use would not be a problem to them. Most studies show that perceived ease of use influences IS success especially in the area of intention usage of the systems (Yusuph et al. 2015; Mtebe \& Roope 2014; Chaouali et al. 2016). Unfortunately, some studies for instance a study by Bhuasiri et al. (2016) observed that perceived ease of use seems unimportant in IS success (intention usage).

Optimism bias is a systematic error in perception of one's own standing relative to group averages; whereas negative events seem less likely to occur to a person than average in relation to a group, and positive events more likely to occur than average compared with the group (Weinstein 1980). More so, it is a tendency for individuals to report that they are less likely than others to be involved in negative events and more likely than others in positive events (Larsen \& Shepperd 2001). Thus, optimism bias is a belief that one's ability is better or more competent than the average users, which will consequently lead to increase in the usage of e-services. Knowledge and ability of people help in such beliefs. Sometimes taxpayers may lack knowledge on what is being provided by the systems; they would want to enquire information from different offices (like the shipping agencies) which is unnecessary wastage of time - instead of viewing from the system. As optimism bias is measured in one's ability to perform a given task, respondents were asked on various questions including: ability to complete e-service transactions; to download forms from tax authority's website; and to recognize fake website. Optimism bias has been used in difference studies for IS success; nevertheless mixed results are observed. Styvén et al. (2014) as well as Carter et al. (2008) indicate that optimism bias has a positive relationship with intention usage of electronic systems. Styvén et al. (2014) opined that optimism bias is a good predictor of IS success on intention usage variable. Yet, other studies such as Schaup et al. (2010) had different observation and found optimism bias to have no significant relationship with e-services in tax electronic filing matters. In some occasions optimism bias is just taken as an indicator of IS Success - technology readiness (Chen et al. 2013).

The above discussion show that different authors view IS success factors differently. Since Tanzania has developed electronic systems in tax operations, and because there are many challenges associated with cargo clearance; this study needed further investigation to cover a specific situation as well as come up with a 
framework useful for e-services especially in public agencies dealing with tax operations for cargo clearance. It was thus proposed that:

$\mathrm{H}_{1}$ : Perceived ease of use is significantly related to IS success.

$\mathrm{H}_{2}$ : Optimism bias on e-services in tax operations is significantly related to IS success.

\section{Methodology}

To test the proposed assumptions, primary data was collected from 223 taxpayers who are involved in cargo clearance. Some of the cargo clearance operations involve using TANCIS. TANCIS integrates different operation such as tax payments from selected banks and lodging import documents. Taxpayers (importers, tax officials and clearing agents) were surveyed to collect data using a self-administered questionnaire in five points Likert scale. These taxpayers were selected randomly and being included in the sample after knowing that they were involved in one way or another in import operations. Importers were investigated through their clearing agents (who operate on their behalf). Most frequent importers are also business operators who were identified through their clearing and forwarding agents. Thus, Dar es Salaam and Coast regions' taxpayers of the Customs and Excise Department of the Tanzania Revenue Authority were the units of analysis. These regions respectively represented the most and least active business centers (United Republic of Tanzania 2014) in order to avoid biases in interpreting the results (Gill \& Johnson 2010). Preliminary analysis such as ensuring completeness in questionnaires and data coding was done to minimize errors (Saunders et al. 2012). A Statistical Package for Social Sciences (SPSS) using Analysis of Moment's Structures (AMOS) tool was applied for data entry. By use of the tool descriptive analyses were obtained and helped to summarize data such as demographic characteristics. Besides, data was tested for validity and reliability. Principal component analysis assisted in determining the constructs of the study. Further, confirmatory factor analysis was run for data validity; whereas, structural equation modeling (SEM) tested the developed hypotheses. SEM was preferable due to presence of unobserved (latent) variables as the study was after users' (taxpayers') perceptions (Bryne 2010).

\section{Study Findings}

This section presents the study findings on demographic characteristics and field data analysis.

\subsection{Respondents' Demographic Characteristics}

223 responses were used for analysis as indicated in Table 1. This sample size is sufficient for use of SEM analysis as it is greater than 200 (Boomsma \& Hoogland 2001). The sample included respondents aged from 18 years old. Sometimes users of different age groups have different perceptions (Ilias et al. 2009; Venkatesh et al. 2003). Also, more than two thirds were male. Users of different sex might have different perceptions in eservices as sex sometimes influences IS success (Al-Shafi \& Weerakkody 2010). The study could include further

other characteristics such as experience, since staff taxpayers were also involved, it could be possible to gather duration rather than experience because systems were established recently (for instance TANCIS - 2014). Therefore, in relation to a surveyed area and with regard to Tanzania businesses as well as tax operations, these results suggest that the sample included taxpayers of different characteristics for representation purposes. Hence, avoiding biases and thus the results could be generalized. 
Table 1. Demographics of Respondents

\begin{tabular}{|lll|}
\hline Variable & \multicolumn{2}{c|}{ Respondents' Details } \\
\hline Sex & 146 & $(65.6 \%)$ \\
Male & 77 & $(34.5 \%)$ \\
Female & & \\
Age (years) & 12 & $(5.4 \%)$ \\
$18-29$ & 71 & $(31.8 \%)$ \\
$30-50$ & 140 & $(62.8 \%)$ \\
$\quad>50$ & & \\
\hline
\end{tabular}

Source: Data analysis of the research

\subsection{Factor Analysis}

Table 2 indicates findings for principal component analysis (PCA), varimax option since factors were not required to correlate much. An option of variables' factor loadings above 0.5 was made to ensure good factors explain the study construct. Three constructs were obtained. Construct number 1 represents taxpayers perceived ease of use; number 2, optimism bias; and number 3 - IS success on intention usage. The results indicate further that data was valid as the Kaiser-Meyer-Olkin (KMO) measure was above 0.5 ; the probability value for the Bartlett's test of sphericity below 0.05 ; and total variance extracted (TVE) of $63 \%$ that is , above $50 \%$. TVE obtained helps to indicate the number of useful factors retained in the study (Gaur \& Gaur 2009). Thus, all the results were acceptable to allow further analysis (Tabachnick \& Fidell 2014; Field 2009).

\subsection{Reliability}

Reliability of constructs was tested using Cronbach alpha measure. All constructs' Cronbach alpha values were above 0.7 , that is, taxpayers' perceived ease of use -0.890 ; optimism bias -0.868 obtained after removal of one item OP5 (able to recognize fake website); and IS success (intention usage) - 0.807 which was achieved after omitting item SucIU4 (I predict to use in the future).

\subsection{Measurement Model}

Several tests were made by running a measurement model through confirmatory factor analysis (CFA). Findings on factor loadings (Table 3) indicate they were all good, that is above 0.5. This test confirmed convergent validity (Tabachnick \& Fidell 2014). 
Table 2. PCA, Constructs and Study Items

\begin{tabular}{|c|c|c|c|}
\hline \multirow[t]{2}{*}{ Items } & \multicolumn{3}{|c|}{ Constructs } \\
\hline & 1 & 2 & 3 \\
\hline It is easy to learn internet usage & .816 & & \\
\hline Systems would be easy to use & .790 & & \\
\hline Easy to input and modify data in electronic systems & .744 & & \\
\hline Using systems would make transactions clearer & .739 & & \\
\hline Learning to use e-services will be easy & .738 & & \\
\hline Instructions for e-services will be easy to follow & .731 & & \\
\hline Can verify authenticity of tax form & & .810 & \\
\hline Able to complete transaction using e-services & & .789 & \\
\hline Can submit information to Tax Authority & & .766 & \\
\hline Can download forms from Authority's website & & .711 & \\
\hline Able to recognize a fake website & & .671 & \\
\hline I predict to use electronic services in tax operations & & & .728 \\
\hline E-service option is my first priority & & & .705 \\
\hline I will use electronic services & & & .688 \\
\hline I intend to use e-services & & & .658 \\
\hline I recommend others to use & & & .656 \\
\hline
\end{tabular}

Extraction Method: Principal Component Analysis.

Rotation Method: Varimax with Kaiser Normalization.

Source: Data analysis 
Table 3. Measurement Model - Factor Loadings

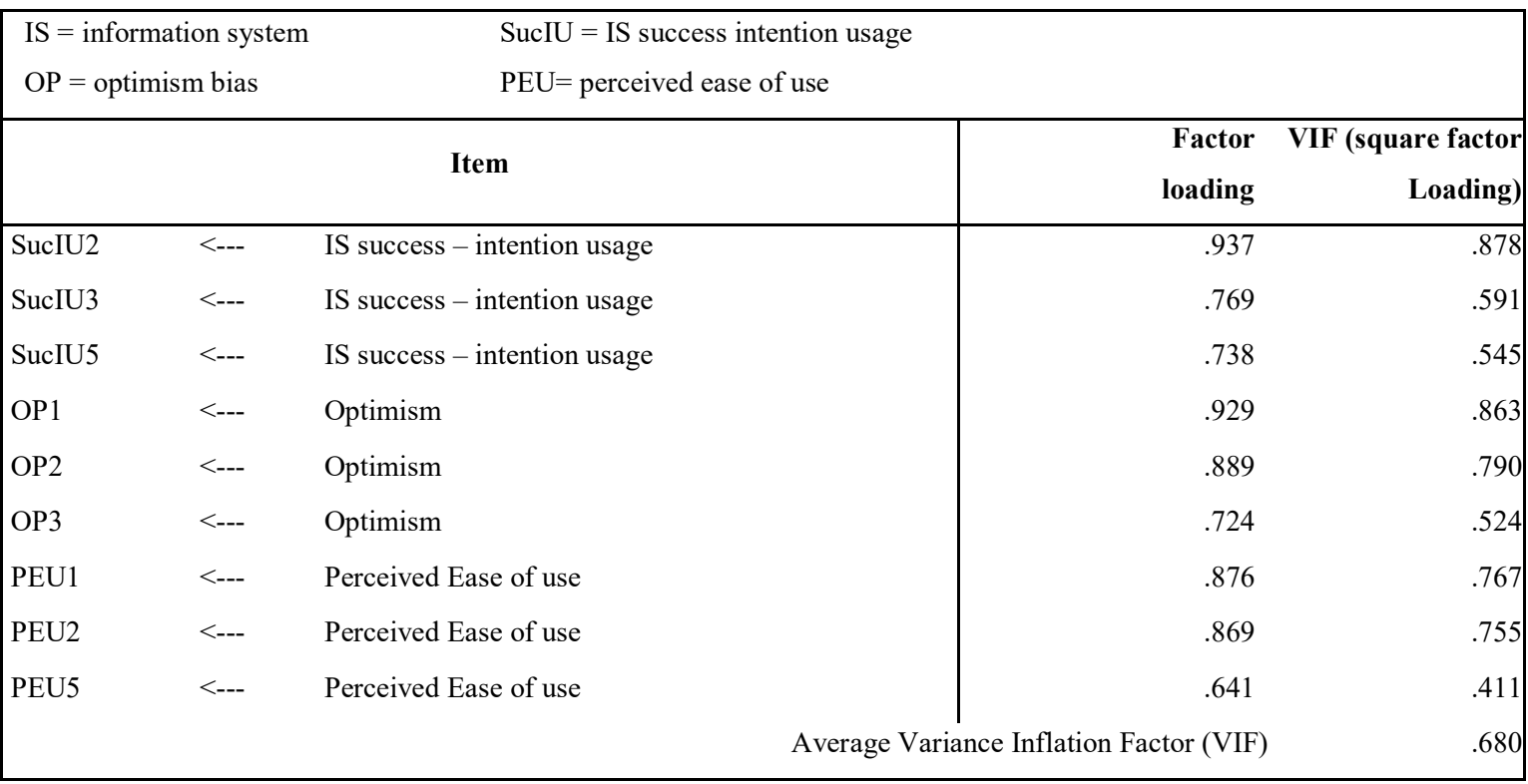

Source: Data analysis

\subsection{SEM Assumptions}

The study confirmed SEM assumptions for normality of data and multicollinearity issues. It was observed that there were no multicolinearity problems since predictor variables' correlations were below 0.85 (Awang 2012), confirming discriminant validity. This test was also supported by the average VIF which was above 0.5 (Table 3). Besides, normality test was conducted (Table 4). This assessment was made using maximum likelihood option found in SPSS - AMOS version 20. The maximum likelihood option is robust and covers several problems which might occur including non-normality (Awang 2012; Hair et al. 2010; Bryne 2010). Nevertheless, results on normality assessment on items' skewness indicate all variables had values below 1.5. Serious non-normality of data may occur when values of skewness exceed 3 (Kline 2011).

Table 4. Assessment of Normality

\begin{tabular}{|l|lr|}
\hline \multicolumn{1}{|c|}{ Variable } & \multicolumn{1}{|c|}{ Description } & Skew \\
\hline PEU5 & Easy to input and modify data & 0.936 \\
PEU2 & Systems would be easy to use & 0.835 \\
PEU1 & It is easy to learn internet usage & 0.961 \\
OP3 & Download forms from websites & 0.573 \\
OP2 & Complete transaction using e-services & 0.586 \\
OP1 & Submission to Tax Authority & 0.645 \\
SucIU5 & I will use electronic services & 0.977 \\
SucIU3 & I recommend other to use & 0.832 \\
SucIU2 & E-service option is my first priority & 0.653 \\
\hline
\end{tabular}

Source: Research data analysis 


\subsection{Structural Model}

The study's structural model is presented in Figure 1. Two predictor variables, optimism bias and perceived ease of use were assessed to determine their influence in IS success for users' intention usage of the systems in customs operations.

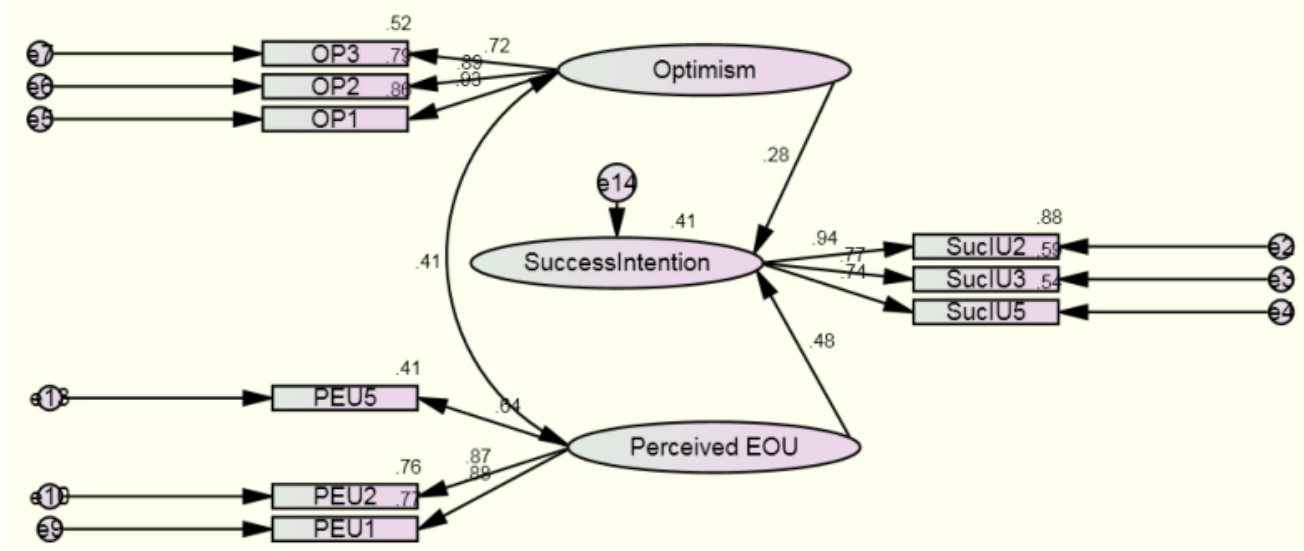

$\mathrm{OP}=$ Optimism bias; PEU = perceived ease of use (EOU); SucIU =IS success - intention usage

Source: Data analysis

Figure 1: Structural Model

\subsection{Hypotheses Testing}

The results on hypotheses testing are presented in Table 5. Both hypotheses were supportive as probability values were below 0.05 . The results suggest that taxpayers' optimistic bias and perceived ease of use are important for IS success (intention usage of developed electronic tax systems). Interpretation of these findings was made after attaining structural model fit by achieving fit indices. By attaining fit indices, the construct validity is achieved implying items explain well the constructs (Awang 2012). Not all fit indices are reported (Hair et al. 2010); thus, accordingly, this study reports on the following fit indices suggested by Awang (2012): comparative fit index $\mathrm{CFI}=0.967$; chi-square per degree of freedom $\chi 2 / \mathrm{DF}=2.59$; root mean square error of approximation - RMSEA $=0.085$; and goodness of fit index - GFI $=0.945$. The value for RMSEA (0.085) is a bit exceeding the threshold value suggested by Hair et al. 2010, however, it was almost in acceptable level (Cangur \& Ercan 2015) due to several reasons, one - being effect on sample size (Kenny \& McCoach 2003; Marsh et al. 2004). Otherwise, all fit indices were on recommended levels for model fitness (Henry \& Stone 1994; Hair et al. 2010). 
Table 5. Hypotheses Testing

\begin{tabular}{|c|c|c|c|}
\hline \multicolumn{3}{|c|}{$\begin{array}{l}\mathrm{P}=\text { probability value } \quad \mathrm{EOU}=\text { Ease of use } \\
* * *=\text { probability value less than } 0.001\end{array}$} & \multirow{2}{*}{$\begin{array}{r}\mathbf{P} \\
\end{array}$} \\
\hline \multicolumn{3}{|c|}{ Items' relationships } & \\
\hline SuccessIntention & $<<---$ & Optimism & $* * *$ \\
\hline SuccessIntention & $<---$ & Perceived EOU & $* * *$ \\
\hline
\end{tabular}

Source: Data analysis

\section{Conclusion}

This research assessed two variables (perceived ease of use and optimism bias) to see their influence to IS success in customs clearance operations since different challenges were experienced. Perceived ease of use and optimism bias in using e-services while clearing cargo were both observed as significant predictors of IS success (intention usage). This implies users will intend to use e-services in tax operations if the systems are ease to use and if they believe that they are confidence as well as capable of using the systems. These findings conform to the previous literature suggesting that the identified variables are good predictors of IS success for intention to use IT (Styvén et al. 2014; Borrero et al. 2014; Venkatesh et al. 2003). Borrero et al. (2014) opine that users who have good skills in ICT, perceived ease of use (effort expectancy) is not an issue since their experience in eservices improves ability to learn. Besides, Schaupp et al. (2010) show that users with knowledge and ability are less susceptible to risk of using e-services than the average person. This therefore highlights the need for electronic systems in tax operations to be easy to use - to accommodate users who are not much knowledgeable in the area.

From the observed findings, this study confirms the relationship suggested by TAM especially on the two variables (perceived ease of use and intention usage for IS success). Moreover, a great significant contribution of the study is the developed framework that considers an integrated variable - optimism bias with TAM variables for the betterment of ICT operations needed in clearing customs consignments. Moreover, the study used valid and reliable data for further validation in similar studies.

Since the optimism bias and perceived ease of use in electronic tax operations (customs clearance of goods) seem to be important for IS success, the study provides some practical recommendations. In order for taxpayer to continue using developed systems for IS success, the study recommends policy makers, practitioners be aligned in further provision of user friendly systems and reliable website applications. For instance, if systems are user friendly, users might intend to use, and furthermore, the need for capacity building would help nontraditional users to acquire confidence in applying the developed systems for IS success; that is, continual usage. Furthermore, the study inputs are useful to researchers and academicians as the research has broadened and confirmed the IS concept in tax administration context.

This study has its limitations; according to the scope (Perry 1998), the study addressed tax operations in government agencies; future research should consider other areas such as private institutions providing eservices to taxpayers like the financial institutions facilitating payment of taxes. Moreover, in achieving model fit some of the items (Table 2) were omitted due to the use of SEM tool which is robust; others should look at 
these variables in the future.

\section{References}

Anees, M., \& Kumar, M. (2017). Perception of taxpayers towards e-file adoption. International Journal of Research - Granthaalayah, 5(11), 325-332.

Arvis, J., Saslavsky, D., Ojala, L., Shepherd, B., Busch, C., Raj, A., et al. (2016). The Logistics Performance Index and Its Indicators. Washngton, DC: The International Bank for Reconstruction and Development/The World Bank.

Awang, Z. (2012). A Handbook on Structural Equation Modeling - SEM. Kuala, Terenggan: Research Gate.

Bhuasiri, W., Zo, H., Lee, H., \& Ciganek, A. (2016). User acceptance of e-government services: Examining an e-tax filing and payment system in Thailand. Information Technology for Development, 22(4), 672-695.

Boomsma, A., \& Hoogland, J. J. (2001). The Robustnessof LISREL modeling revisited. In R. Cudeck, S. du Toit and D. Sorbom (EDS) Structural Equation Modeling: Present and Future. Chikago: Scientific Software International.

Borrero, J., Yousafzai, S., Javed, U., \& Page, K. (2014). Expressive participation in Internet social movements: Testing the moderating effect of technology readiness and sex on student SNS Use. Computers in Human Behavior, 30, 39-49.

Bryne, B. (2010). Structure Equation Modeling with AMOS: Basic Concepts Applications and Programs. New York, NY: Routledge Taylor and Francis Group.

Cangur, S., \& Ercan, I. (2015). Comparison of Model Fit Indices Used in Structural Equation Modeling Under Multivariate Normality. Journal of Modern Applied Statistical Methods, 14(1), 152-167.

Carter, L., Schaupp, L., \& Evans, A. (2008). Antecedents to e-File Adoption: The U.S. Perspective. Proceedings of the 41st Hawaii International Conference on System Sciences, (pp. 1-7).

Chaouali, W., Yahia, I., Charfeddine, L., \& Triki, A. (2016). Understanding citizens' adoption of e-filing in developing countries: an empirical investigation. Journal of High Technology Management Research, 1-16.

Charfeddine, L., \& Nasri, W. (2013). The Behavior Intention of Tunisian Banks' Customers on Using Internet Banking. INternational Journal of Innovation in the Digital Economy, 4(1), 16-30.

Chen, S., Liu, M., \& Lin, C. (2013). Integrating Technology Readiness into the Expectation-Confirmation Model: An Empirical Study of Mobile Services. Cyberpsychology, Behavior, and Social Networking, 16(8), 604-612.

Chimilila, C., Sabuni, C., \& Benjamin, A. (2014). Trade Facilitation in EAC Customs Union: Its Achievement and Implementation in Tanzania. Journal of Economics and Sustainable Development, 5(25), 1-15.

Davis, F. D. (1989). Perceived usefulness, perceived ease of use and user acceptance of information technology. MIS Quarterly, Vol 13 NO. 3, 319-339.

AECCMA (2004). The East African Community (EAC) Customs Management Act. Dar es Salaam, The Government Printer by order of EAC

Field, A. (2009). Discovering Statistics Using SPSS. London, UK: Sage Publications Ltd.

Fishbein, M., \& Ajzen, I. (1975). Belief, Attitude, Intention and Behavior; An Introduction to Theory and Research. Ontario: Addison-Wesley. 
Gaur, A. S., \& Gaur, S. S. (2009). Statistical Methods for Practice and Research - A Guide to Data Analysis Using SPSS (2nd ed.). London: Sage Publications.

Gill, J., \& Johnson, P. (2010). Research Methods for Managers. London: Sage.

Hair, J., Black, W., Babin, B., \& Anderson, R. (2010). Multivariate Data Analysis (7 ed.). Upper Saddle River, NJ: Pearson Prentice Hall.

Henry, J., \& Stone, R. (1994). A structural equation model of enduser satisfaction with a computer-based medical information systems. Information Resources Management Journal, 7, 21-33.

Ilias, A., Mohd, Z., \& Mohd, R. Y. (2009). Taxpayers' Attitude in Using E-filing System: Is There any Significant Difference Among Demographic Factors? Journal of Internet Banking and Commerce, 14(1)

Kenny, D., \& McCoach, D. (2003). Effect of the number of variables on measures of fit in structural equation modeling. Structural Equation Modeling: A Multidisciplinary Journal, 10(3), 333-351.

Kline, R. (2011). Principle and Practice of Structural Equation Modeling. New York, NY: The Gulfford Press.

Kumar, S., \& Gupta, S. (2017). A study on income tax payers perception towards electronic filing. Journal of Internet Banking and Commerce, 22(S7), 1-14.

Larsen, M., \& Shepperd, J. (2001). Do moderators of the optimistic bias affect personal or target risk estimates? a review of the literature. Personality and Social Psychology, 5(1), 74-95.

Marsh, H., Hau, K., \& Wen, Z. (2004). In search of golden rules: Comment on hypothesis-testing approaches to setting cutoff values for fit indexes and dangers in overgeneralizing $\mathrm{Hu}$ and Bentler's (1999) findings. Structural Equation Modeling: A Multidisciplinary Journal, 11(3), 320-341.

McFarland, D., \& Hamilton, D. (2006). Adding contextual specificity to the technology acceptance model. Computers in Human Behaviour, 22(3), 427-447.

Moorthy, M., Samsuri, A., \& Hussin, S. (2014). E-Filing Behaviour among Academics in Perak State in Malaysia. Technology and Investment, 5, 79-94.

Mtebe, J. S., \& Raisamo, R. (2014). Investigating students' behavioural intention to adopt and use mobile learning in higher education in East Africa. International Journal of Education and Development(3), 4-20.

Okazaki, Y. (2018). Doing Business and its Customs-related Issues: A study on the Trading across Borders Indicators. Accessible at WCO website: www.wcoomd.org.: WCO.

Perry, C. (1998). A Structured Approach for Presenting Research Theses. Australasian Marketing Journal, 6(1), 63-86.

Ramayah, T., Yusoff, M., Jamaludin, N., \& Ibrahim, A. (2009). Applying the Theory of Planned Behavior (TPB) to Predict Internet Tax Filling Intention. International Journal of Management, 26(2), 272-284.

Rana, N., Dwivedi, Y., Williams, M., \& Weerakkody, V. (2015). Investigating success of an e-government initiative: Validation of an integrated IS success model. Information Systems Frontiers, 17(1), 127-142.

Saunders, M., Lewis, P., \& Thornhill, A. (2012). Research Methods for Business Students (6th ed.). London: Harlow Pearson Education Limited.

Schaupp, L., Carter, L., \& Hobbs, J. (2010). Electronic Tax Filing: the Impact of Reputation and Security on Adoption. Proceedings of the 43rd Hawaii International Conference on System Sciences, (pp. 1-10).

Styvén, M., Wallström, Å., Engström, A., \& E, S. (2014). To Use or not to Use: Road Bumps for Citizens' Adoption of E-services. An International Journal on Information Technology, Action, Communication and 
Workpractices, 8(1), 25-42.

Tabachnick, B., \& Fidell, L. (2014). Using Multivariate Statistics. Harlow: Pearson.

Tanzania Revenue Authority . (2017). Tanzania Customs Information, Logistics Capacity Assessment - Digital Logistics Capacity Assessment. Retrieved on 24th September 2018 from http//www.tra.go.tz/index.php: TRA.

Teo, T., \& Zhou, M. (2014). Explaining the Intention to Use Technology among University Students: a Structural Equation Modeling Approach. J Comput High Educ, 26, 124-142.

Teo, T., Srivastava, S., \& Jiang, L. (2008). Trust and Electronic Government Success: An Empirical Study. Journal of Management information system, 25(3), 99-131.

United Republic of Tanzania. (2014). How E-government Contributes to Inclusive and Sustainable Development: Tanzania Experience. Dar es Salaam: E-government Agency.

Venkatesh, V., \& Davis, F. (2000). A theoretical extension of the technology acceptance model: four longitudinal field studies. Management Science, 46(2), 186-204.

Venkatesh, V., Morris, M., Davis, G., \& Davis, F. (2003). Users' acceptanve of information technology: toward a unified view. MIS Quarterly, 27(3), 287-294.

Venkatesh, V., Thong, J., \& Xu, X. (2012). Consumer Acceptance and Use of Information Technology: Extending the Unified Theory of Acceptance and Use of Technology. MIS Quarterly, 36(1), 157-178.

Weinstein, N. (1980). Optimistic Bias about personal risks. Science, 246, 1232-1233.

Yusup, M., Hardiyana, A., \& Sidharta, I. (2015). User Acceptance Model on E-Billing Adoption: A Study of Tax Payment by Government Agencies. Asia Pacific Journal of Multidisciplinary Research, 3(4), 150-157. 